\title{
Respiratory Care Year in Review 2013: Neonatal Respiratory Care, Pulmonary Function Testing, and Pulmonary Rehabilitation
}

\author{
Craig D Smallwood RRT, Jeffrey M Haynes RRT RPFT, Brian W Carlin MD FAARC, \\ and Dean R Hess PhD RRT FAARC
}

\author{
Introduction \\ Neonatal Respiratory Care \\ High-Frequency Oscillatory Ventilation \\ Noninvasive Ventilation \\ Inhaled Nitric Oxide \\ Pulmonary Function Testing \\ Testing Guidelines \\ Pulmonary Function Testing Quality \\ Reference Equations \\ Exercise Testing \\ Spirometry and Disease Patterns \\ Pulmonary Rehabilitation \\ Physiology (Exercise Training) \\ Physiology (Arm Exercise) \\ Impact on Exacerbations and Health Care Utilization \\ Telerehabilitation \\ COPD and Comorbidities (eg, Sleep-Related Disorders) \\ Other General Review Articles
}

\begin{abstract}
Respiratory care practice includes neonatal respiratory care, pulmonary function testing, and pulmonary rehabilitation. The purpose of this paper is to review the recent literature related to these topics in a manner that is most likely to have interest to the readers of RESPIRATORY CARE. Key words: exercise testing; high-frequency oscillatory ventilation; inhaled nitric oxide; noninvasive ventilation; pulmonary function testing; pulmonary rehabilitation; spirometry. [Respir Care 2014;59(5):777-787. () 2014 Daedalus Enterprises]
\end{abstract}

\section{Introduction}

It remains a challenge to review the literature relevant to one's practice and then update that practice based on the

\footnotetext{
Mr Smallwood is affiliated with the Department of Anesthesia, Division of Critical Care Medicine, Respiratory Therapy Department, Boston Children's Hospital and the Department of Anesthesia, Harvard Medical School, Boston, Massachusetts. Mr Haynes is affiliated with the Respiratory Therapy Department, St. Joseph Hospital, Nashua, New Hampshire. Dr Carlin is affiliated with the Altoona Regional Health System,
}

current evidence. At the American Association for Respiratory Care Congress 2013, RESPIRATORY CARE presented a series of lectures on the theme of "Year in Review." Topics were chosen that are likely to have special interest to the readers of the Journal. In this paper, we publish topics

\footnotetext{
Altoona, Pennsylvania, and Washington Hospital, Washington, Pennsylvania. Dr Hess is affiliated with the Respiratory Care Department, Massachusetts General Hospital, and the Department of Anesthesia, Harvard Medical School, Boston, Massachusetts.
} 
related to neonatal respiratory care, pulmonary function testing, and pulmonary rehabilitation.

\section{Neonatal Respiratory Care}

\section{High-Frequency Oscillatory Ventilation}

Nonconventional forms of mechanical ventilation, including high-frequency oscillatory ventilation (HFOV) and high-frequency jet ventilation, have been used with neonates for decades. The physiologic rationale for doing so includes exposure to very small tidal volumes $\left(\mathrm{V}_{\mathrm{T}}\right)$ and lower peak airway pressures, which experimental data suggest may reduce ventilator-induced lung injury. However, randomized controlled trials comparing HFOV, which has been studied more thoroughly than high-frequency jet ventilation, to conventional mechanical ventilation have failed to demonstrate a clear benefit. A Cochrane Review update was recently conducted. ${ }^{1}$ The meta-analysis included 17 studies of 3,652 infants who received early elective HFOV, usually within $12 \mathrm{~h}$ of life. Overall, the authors reported no significant reductions in the risk of death or chronic lung disease at 36-37 weeks postmenstrual age or at discharge. However, the rate of retinopathy of prematurity was reduced overall. In an accompanying commentary, Soll ${ }^{1}$ points out the important fact that practice among the trials included in the review varied, as did the patient characteristics, and this may account for the inconsistent results observed in the various randomized controlled trials.

Despite the lack of evidence suggesting a clear benefit for HFOV, it remains a common form of ventilation in the neonatal ICU (NICU), with as many as one of 5 infants receiving HFOV during the NICU course. ${ }^{1}$ To identify objective measures of optimal HFOV settings, which could minimize practice variations and individualize treatment, Tingay et $\mathrm{al}^{2}$ applied various noninvasive monitors to describe the pressure-volume curve characteristics during

\footnotetext{
A version of this paper was presented by Mr Smallwood, Mr Haynes, and Dr Carlin at the 59th International Respiratory Convention \& Exhibition of the AARC Congress 2013, held November 16-19, 2013, in Anaheim, California.
}

Mr Smallwood discloses relationships with GE Healthcare, Maquet, and Hill-Rom. Mr Haynes has disclosed no conflicts of interest. Dr Carlin discloses relationships with GlaxoSmithKline, Boehringer Ingelheim, Forest Laboratories, Philips Respironics, and Breathe Technologies. Dr Hess discloses relationships with Philips Respironics, Pari, Covidien, Maquet, Merck, and Bayer.

Correspondence: Dean R Hess PhD RRT FAARC, Respiratory Care, Massachusetts General Hospital, 55 Fruit Street, Boston, MA 02114. E-mail: dhess@partners.org.

DOI: $10.4187 /$ respcare. 03242
HFOV. During a systematic increase and then decrease in mean airway pressure during $\mathrm{HFOV}$, the authors identified clear relationships between transcutaneous $\mathrm{CO}_{2}, \mathrm{~V}_{\mathrm{T}}$ measured by proximal flow sensor and respiratory inductive plethysmography, minute ventilation, and mean airway pressure $\left(\overline{\mathrm{P}}_{\mathrm{aw}}\right)$ or end-inspiratory lung volumes measured by inductive plethysmography. They applied the clinical data to the sigmoidal pressure-volume loop described by Venegas et al. ${ }^{3}$ Interestingly, the transcutaneous $\mathrm{CO}_{2}, \mathrm{~V}_{\mathrm{T}}$, and minute ventilation were optimized in a relatively small window of applied $\overline{\mathrm{P}}_{\mathrm{aw}}$. Also of note, oxygenation appeared to be a poor indicator of optimal lung volume and/or compliance in that an acceptable $\mathrm{S}_{\mathrm{pO}_{2}}$ was observed over a wide range of $\overline{\mathrm{P}}_{\mathrm{aw}}$ and was actually increased compared to the other measures. It appears that oxygenation alone is a poor indicator of optimal lung volume in infants requiring HFOV. Although the data presented in this study did not include long-term outcomes, individualization of respiratory support at the bedside is an interesting area of research, and further studies replicating these results and observing long-term outcomes such as duration of ventilation and mortality are needed.

\section{Noninvasive Ventilation}

The rationale for supporting premature infants with noninvasive ventilation (NIV) is rooted in the observation that many infants can achieve adequate oxygenation and ventilation without the use of an endotracheal tube and its associated risks, including infection, agitation, chronic lung disease/bronchopulmonary dysplasia (BPD), and longer NICU stay. Previously published studies identified a role for NIV in this patient population. ${ }^{4,5}$ Wilinska et $\mathrm{al}^{6}$ studied the practice of 18 Polish NICUs and identified the practice shift to NIV and the associated outcomes. Although these data are observational, they represent 7 years and 5,551 infants treated in the NICU. The study included 2 groups for comparison, a pre-adoption group, in which NIV was only sparsely encouraged, and a post-adoption group, in which clinicians were encouraged to utilize NIV much more readily. The use of NIV as a first line of therapy in neonates increased by $19 \%$, and usage postextubation increased by $36 \%$ during the study period. Overall, NIV was associated with a reduction in mortality for infants with an estimated gestational age of $<32$ weeks from 11 to $7 \%(P<.001)$. In gestational age subgroup analysis, it was observed that the reduction in mortality was most evident in those infants $<28$ weeks of age. Furthermore, the authors looked at a composite outcome, including the incidence of severe retinopathy of prematurity and grade III BPD. Retinopathy of prematurity and BPD occurred more commonly in the post-adoption group, but this finding did not reach statistical significance. It is likely that the increased incidence of retinopathy of pre- 
maturity and BPD can be attributed to those infants who previously would have died but who now survive to ICU discharge. Overall, this observational study adds weight to the evidence suggesting a role for NIV in premature infants in the NICU. Because this study was not controlled, variability in practice may have been a confounding factor.

It has been suggested that differences in NIV approach may play an important role in clinical outcomes. Nasal intermittent positive-pressure ventilation (NIPPV) is a mode of NIV that increases $V_{T}$ and supports ventilation. $A$ number of small trials comparing nasal CPAP with NIPPV have been conducted previously but failed to demonstrate consistent results, and meta-analyses differed in which trials were included. ${ }^{7-9}$ Kirpalani et al ${ }^{10}$ therefore conducted a randomized controlled trial comparing NIPPV and nasal CPAP in a group of 1,009 infants with birthweight of $<1000 \mathrm{~g}$ in 34 NICUs in 10 countries. Enrolled subjects were randomized to receive either nasal CPAP or NIPPV. Primary outcomes included death before 36 weeks and BPD at 36 weeks postmenstrual age. No significant differences were observed between the groups, suggesting that NIPPV did not prove to be superior to nasal CPAP. The results were adjusted for various factors (including sex, receipt of antenatal steroids, and use of caffeine), none of which demonstrated an effect upon the outcome. Additionally, no differences in respiratory or other outcomes were observed (including air leaks, pulmonary hemorrhages, nosocomial sepsis, retinopathy of prematurity, nasal trauma, or necrotizing enterocolitis). This study represents a well-conducted trial of NIPPV and nasal CPAP. However, it was not designed to control for the effects of patient-ventilator synchrony during NIPPV. Indeed, leaks, weak respiratory efforts, small $\mathrm{V}_{\mathrm{T}}$ values, and technological limitations of flow and pressure measurement during NIV culminate to limit the ability of a device to synchronize respiratory effort with inspiratory pressure. If further trials are to be conducted comparing NIPPV and CPAP, this should be addressed.

Overall, the application of NIV in neonates appears to be associated with reductions in mortality and other important clinical outcomes. Furthermore, there do not appear to be differences in mortality or incidence of BPD among extremely-low-birthweight infants supported with either NIPPV or CPAP.

\section{Inhaled Nitric Oxide}

Inhaled nitric oxide (INO) is a potent inhaled pulmonary vasodilator that is approved for use in newborns with hypoxic respiratory failure. ${ }^{11} \mathrm{~A}$ randomized controlled trial comparing INO in term and near-term infants with hypoxic respiratory failure has previously been reported, and it did not show a difference between infants who received early INO and the control group. ${ }^{12}$ However, because the study design did not yield a large difference in the oxygenation index (OI) between the early INO group and the control group that was eligible to receive rescue INO if the OI progressed to $>25$, the authors concluded that the findings of the earlier publications were likely limited by this effect. Therefore, these authors revised the study design and then applied it to the data from the previous publication. For infants randomized to receive INO, treatment at an $\mathrm{OI}<20$ was associated with a decreased risk of extracorporeal membrane oxygenation support and/or death compared to those infants who received INO at OI $\geq 20$ (odds ratio $0.25,95 \%$ CI $0.08-0.67, P=.01$ ). ${ }^{13}$ Furthermore, the cumulative probability of discharge for infants in the revised early INO group (OI $<20$ ) was statistically different by Kaplan-Meier analysis compared to the control (no INO), with those receiving early INO tending to be discharged earlier. Conversely, later application of INO $(\mathrm{OI} \geq 20)$ was no different from the control group in terms of probability of discharge.

In addition to important respiratory and general outcomes such as stay and survival, INO has been suggested to play an important role in lung and brain development. ${ }^{14,15}$ Durrmeyer et $\mathrm{al}^{16}$ reported the findings of a multi-center randomized controlled trial to assess the potential benefit of INO in neurodevelopmental and respiratory outcomes in neonates born at $<29$ weeks of gestation. Upon enrollment in the study, subjects received either INO at $5 \mathrm{ppm}$ or placebo for 7-21 days. Assessments were conducted at 1 and 2 years, including cognitive scoring; overall neurodevelopmental disabilities; various neurologic, vision, and hearing outcomes; and hospitalizations. This study suggests that INO has no effect on brain and lung development. Although the authors intend to complete the study with a 7-year follow-up, it seems unlikely that significant differences will be observed for any of the important outcomes.

\section{Pulmonary Function Testing}

\section{Testing Guidelines}

The American Thoracic Society (ATS) published $2 \mathrm{im}$ portant testing guidelines in 2013. The ATS workshop report on optimal lung function tests for monitoring cystic fibrosis, $\mathrm{BPD}$, and recurrent wheezing in children $<6$ y old evaluated 6 pulmonary function tests (PFTs): raised-volume rapid thoracic compression and plethysmography, spirometry, specific airway resistance, interrupter technique, impulse oscillometry, and multiple-breath washout/lung clearance index. ${ }^{17}$ All of these tests were judged to be both safe and feasible. However, additional training is required for the raised-volume rapid thoracic compression since infant sedation is required. A call for more robust reference equations was made because currently available equations tend to be device-specific and 
under-represent non-white populations. Additional recommendations to address weaknesses in current practice include a better definition of what constitutes a significant change in lung function and clinical studies to address the impact of infant and preschool testing on patient outcomes.

The second ATS clinical practice guideline is on the topic of exercise-induced bronchoconstriction. ${ }^{18}$ This clinical guideline addresses the pathogenesis, diagnosis, and treatment of exercise-induced bronchospasm. In terms of diagnostic testing, the guideline recommends that serial measures of pulmonary function be made after exercise and that $\mathrm{a} \geq 10 \%$ fall in $\mathrm{FEV}_{1}$ is reflective of exerciseinduced bronchoconstriction. Peak expiratory flow is regarded as inferior to $\mathrm{FEV}_{1}$ as a diagnostic signal. Acceptable surrogates for exercise challenge testing include mannitol dry powder challenge, hypertonic saline inhalation, and eucapnic voluntary hyperventilation.

\section{Pulmonary Function Testing Quality}

One of the most effective elements of a PFT laboratory quality assurance program is technologist performance monitoring and feedback. The Lung Health Study Research Group reported that sustainable improvements in technologist performance can be realized when technologists are given ongoing feedback on their performance. ${ }^{19}$ Several epidemiologic studies have employed similar programs and have comparable results. ${ }^{20-22}$ Borg et $\mathrm{al}^{23}$ compared 2 clinical PFT laboratories before and after the implementation of a technologist monitoring and feedback program. In 2004, the percentage of spirometry tests satisfying ATS/ European Respiratory Society (ERS) acceptability and reproducibility criteria was $61 \%$ in laboratory 1 and 59\% in laboratory 2. Following this initial assessment, laboratory 1 implemented technologist monitoring and feedback, whereas laboratory 2 did not. A repeat survey of spirometry quality in 2008 revealed that ATS/ERS quality adherence rose to $92 \%$ in laboratory 1 , whereas in laboratory 2 , the quality remained poor at only $65 \%$ adherence.

Another study of technologist performance was performed in an occupational health surveillance program at an Iranian oil refinery, where 2 technologists monitored the respiratory health of 1,004 workers. ${ }^{24}$ Spirometry quality was assessed before and after completion of a National Institute for Occupational Safety and Health spirometry course and implementation of a technologist performancemonitoring program. Before the intervention, only 29.6 and $63.3 \%$ of tests met expiratory time and extrapolated volume criteria, respectively. Following the intervention, these quality end points were accomplished in $>90 \%$ of tests, and the measured mean FVC and $\mathrm{FEV}_{1}$ for the group had increased. In an accompanying editorial, Enright and Schermer ${ }^{25}$ reported their experience in monitoring spirometry quality in which reimbursement became contin- gent on test quality. Before reimbursement contingency, $\sim 60 \%$ of spirometry tests were judged to be of acceptable quality, but this increased to $95 \%$ after reimbursement became contingent on test quality.

Haynes ${ }^{26}$ compared the quality of spirometry and diffusion capacity of the lung for carbon monoxide $\left(\mathrm{D}_{\mathrm{LCO}}\right)$ tests in consecutive patients $\geq 80$ y old over a 22-month period. A cohort of 40-50-y-old patients served as a control group. $92.6 \%$ of elderly group and $91.5 \%$ of control group spirometry tests satisfied all ATS/ERS acceptability and reproducibility criteria $(P=.84) .84 .9 \%$ of elderly group and $88.5 \%$ of control group $\mathrm{D}_{\mathrm{LCO}}$ tests satisfied all ATS/ERS acceptability and reproducibility criteria $(P=.45)$. The data clearly show that elderly patients referred to a hospital-based PFT lab can be expected to achieve spirometry and $\mathrm{D}_{\mathrm{LCO}}$ quality scores comparable to younger adult patients.

\section{Reference Equations}

Proper performance of PFTs is only part of the diagnostic process. Once collected, it must be determined whether the observed data are consistent with normal lung function or possibly a signal of disease. Moreover, once an abnormal state is identified, properly quantifying the degree of impairment is critical to assigning an appropriate prognosis and treatment plan. A number of reference equations were published this past year, including equations for spirometry, ${ }^{27}$ exercise testing, ${ }^{28}$ impulse oscillometry, ${ }^{29}$ and the lung clearance index. ${ }^{30}$ The most notable of these are the Global Lungs Initiative (GLI) spirometry equations. ${ }^{27}$ Reference equations for PFTs have been used for many years. However, the equations currently in use have limitations, including the possibility of outdated data sets, limited number of subjects, age range, geographical coverage, corrections for race, and perhaps less than ideal statistical techniques. ${ }^{31}$

The GLI was formed by the ERS in 2010 with the goal of producing a global reference equation for spirometry testing that would span a wide age range, incorporate multiracial sampling, and use better statistical techniques. The published reference equations include data from 74,187 healthy subjects from 72 centers in 33 different countries. In addition, the GLI predicted equations span ages 3-95 y and include race corrections for African Americans, North East Asians, and South East Asians. An all-age equation negates the need to use different equations for different age groups and provides a seamless transition through the stages of life. ${ }^{31}$

The GLI equations revolutionize the definition of spirometric normality with the use of the lambda-mu-sigma statistical method. Use of the lambda-mu-sigma method represents a clear departure from traditional multiple regression analysis. As PFT interpretation moves away from 
using fixed thresholds and defining the lower limit of normal as $80 \%$ of predicted ${ }^{32}$ and toward reliance on the 5 th percentile, the definition of the lower limit of the normal range needs to be robust. The lambda-mu-sigma method defines the lower limit of the normal range as the 5th percentile of $\mathrm{z}$ scores, which does not assume homoscedastic variance around the center of normality. ${ }^{33}$

The GLI predicted equations have been compared to commonly used reference equations in both children and adults. Quanjer and Weiner ${ }^{34}$ compared the GLI reference equations with other commonly used equations in 4,780 children and adolescents. The GLI equations produced similar results as the reference equations from Hankinson et a ${ }^{35}$ and Wang et a ${ }^{36}$; however, there was poor agreement with the equations of Knudson et al, ${ }^{37}$ Polgar and Promadhat, ${ }^{38}$ and Zapletal et al. ${ }^{39}$ Quanjer et al ${ }^{40}$ compared GLI reference equations with those from Hankinson et $\mathrm{al}^{35}$ and the European Community for Steel and $\mathrm{Coal}^{41}$ in 17,572 adults. The lower limit of the normal range for FVC produced fewer subnormal values when using the GLI versus Hankinson et al reference equations and more subnormal values when comparing the GLI versus European Community for Steel and Coal reference equations.

\section{Exercise Testing}

The 6-min walk test (6MWT) is a submaximal exercise test used to assess a patient's cardiopulmonary function state and to assess therapy response in patients with heart, lung, and pulmonary vascular disease. ${ }^{42}$ However, the 6MWT suffers from a lack of reproducibility, which makes a change in the $6 \mathrm{MWT}$ of limited value. ${ }^{43,44}$ Weir et al ${ }^{45}$ theorized that 6MWT variability could originate from patient instructions that emphasize endurance rather than walking speed. To test this hypothesis, the investigators assessed different patient instructions on the distance walked by patients with pulmonary arterial hypertension, idiopathic pulmonary fibrosis, and other interstitial lung diseases. The mean walking distance was $52.7 \mathrm{~m}$ farther when the patients were instructed to walk "as fast as you can" than when given the standard ATS instructions to walk "as far as you can." 42 A continuation of this research path has the potential to improve the reproducibility and clinical impact of the 6MWT.

While body weight has an impact on pulmonary function and exercise capacity, actual body weight is not typically used in pulmonary function reference equations because pulmonary function may be overestimated in obese patients and underestimated in gaunt patients. One area of cardiopulmonary diagnostic testing that has continued to use actual body weight to produce predicted values is cardiopulmonary exercise testing. Specifically, predicted maximum oxygen consumption $\left(\dot{\mathrm{V}}_{\mathrm{O}_{2}}\right)$ uses actual body weight as a variable in commonly used reference equations. Ah- madian et al ${ }^{46}$ compared the predicted maximum $\dot{\mathrm{V}}_{\mathrm{O}_{2}}$ using actual body weight against ideal body weight in 220 patients. The investigators observed less overestimation of maximum $\dot{\mathrm{V}}_{\mathrm{O}_{2}}$ when using ideal body weight instead of actual body weight in the calculation of maximum $\dot{\mathrm{V}}_{\mathrm{O}_{2}}$. This study strengthens the case that ideal body weight should become the standard to calculate maximum $\dot{\mathrm{V}}_{\mathrm{O}_{2}}$.

Another interesting study of cardiopulmonary exercise test interpretation was conducted by Kaminsky et al. ${ }^{47}$ While maximum $\dot{\mathrm{V}}_{\mathrm{O}_{2}}$ is commonly used to classify maximum exercise capacity, some subjects achieve work loads disproportionate to their maximum $\dot{\mathrm{V}}_{\mathrm{O}_{2}}$. They found that subjects whose peak work load exceeded maximum $\dot{\mathrm{V}}_{\mathrm{O}_{2}}$ by $\geq 15 \%$ exercised longer and had a lower body mass index and higher breathing reserve and peak heart rate. Subjects who had the opposite relationship (maximum $\dot{\mathrm{V}}_{\mathrm{O}_{2}} \leq$ peak work load by $15 \%$ ) had opposing physiologic characteristics (ie, shorter exercise time, higher body mass index, lower breathing reserve, and lower peak heart rate). These data lead to a better understanding of the physiologic patterns encountered during cardiopulmonary exercise testing and indicate that peak work load may provide a more accurate assessment of exercise capacity in elite athletes and fit individuals.

\section{Spirometry and Disease Patterns}

Pulmonary function testing would be merely a footnote in medical history without the early observation and undeniable truth that PFT data are distinctly different in health and disease. ${ }^{48}$ In 2013, our understanding of how disease is reflected in spirometry testing was advanced.

Majid et al ${ }^{49}$ studied the flow-volume loops of 76 patients with symptomatic moderate-to-severe tracheobronchomalacia. Moderate-to-severe disease was defined as $>75 \%$ airway narrowing in the trachea, main bronchi, or bronchus intermedius during a forced expiratory maneuver performed under endoscopic observation. While most patients $(81.6 \%)$ were found to have a low peak expiratory flow, no pathognomonic flow-volume loop pattern was identified. In fact, several flow-volume loop patterns were observed: biphasic (19.7\%), normal loop (17.1\%), notched pattern $(9.2 \%)$, and expiratory oscillations $(2.6 \%)$. Spirometry and flow-volume loop analysis clearly lack sensitivity and pathognomonic features to diagnose or rule out tracheobronchomalacia. A definitive diagnosis of tracheobronchomalacia requires computed tomography or bronchoscopy.

As mentioned earlier, most elderly patients can produce high-quality spirometry. ${ }^{29}$ However, there will always be some patients who are incapable of producing meaningful spirometry data. An interesting option in such patients is to examine the flow-volume loop of tidal breaths. Nozoe et al ${ }^{50}$ examined spontaneous expiratory flow-volume loops 
in elderly patients with and without COPD. A concave expiratory flow pattern and a rectangular area ratio $<0.5$ were found to be reflective of very severe air-flow obstruction. The usefulness of spontaneous expiratory flowvolume loops in younger patients and those with less severe air-flow obstruction is unclear.

The forced expiratory flow during the middle half of the FVC maneuver is used by many clinicians to assess small airway function and detect early airway disease. However, it has a very wide range of normality ${ }^{27}$ and can be greatly affected by the forced expiratory time. Morris et $\mathrm{al}^{51} \mathrm{ex}-$ amined the ability of $\mathrm{FEV}_{3} / \mathrm{FVC}$ to identify early airway disease. Patients with an isolated reduction in $\mathrm{FEV}_{3} / \mathrm{FVC}$ were more likely to be smokers and had signs of air trapping and loss of diffusion capacity.

\section{Pulmonary Rehabilitation}

Pulmonary rehabilitation is a core component in the management of patients with chronic lung disease. Ongoing research has shown how to improve pulmonary rehabilitation to provide better care for such patients. Over the last year, several key articles have been published in the field that should ultimately influence how pulmonary rehabilitation is performed.

Several evidence-based clinical practice guidelines and consensus statements regarding pulmonary rehabilitation have been published over the last 3 decades..$^{52,53}$ Most recently, the ATS and the ERS issued an updated joint statement on pulmonary rehabilitation that included a new definition of pulmonary rehabilitation and highlighted key concepts and major advances in the field that have occurred over the last decade. ${ }^{54}$

This ATS/ERS statement was developed by a multinational multidisciplinary group of 46 clinical and research experts with a charge to update the previous ATS/ERS statement. The panel included experts from relevant clinical and nonclinical disciplines and included a methodologist with expertise in the field. Multiple electronic databases were searched, and reference lists of relevant articles were reviewed to allow synthesis of the evidence and evaluation for sources of bias. The document placed pulmonary rehabilitation within the concept of integrated care as defined by the World Health Organization as "a concept bringing together inputs, delivery, management and organization of services related to diagnosis, treatment, care, rehabilitation and health promotion." Several noteworthy advances in pulmonary rehabilitation are discussed within the statement, and it was developed in sections including exercise training, conditions other than COPD, behavior change in collaborative self-management, body composition, physical activity, timing of pulmonary rehabilitation, benefits from maintenance therapy, patient-centered outcomes, and program organization.
The following definition of pulmonary rehabilitation was made: "Pulmonary rehabilitation is a comprehensive intervention based on a thorough patient assessment followed by patient-tailored therapies which include, but are not limited to, exercise training, education, and behavior change, designed to improve the physical and psychological condition of people with chronic respiratory disease and to promote the long-term adherence to health-enhancing behaviors." This definition includes the principles of integrated care and health behavior change that should be used by pulmonary rehabilitation professionals to address the complex nature of COPD, its multisystem manifestations, and frequently associated comorbidities.

There is increased evidence for the use and efficacy of a variety of forms of exercise training as part of a pulmonary rehabilitation program. It is recommended that before starting an exercise training program, an assessment of each individual's exercise ability is needed to individualize the exercise prescription, to evaluate the potential need for supplemental oxygen, and to help ensure the safety of the intervention.

Exercise training typically includes endurance training of either high or low intensity. High-intensity training is usually prescribed 3-5 times per week at a high level of intensity of continuous exercise $(>60 \%$ maximal work rate) for 20-60 min per session. Low-intensity training can be used for those patients unable to tolerate the higher intensity training level.

Other types of exercise training (eg, interval training, resistance training, strength training, upper limb training, and transcutaneous neuromuscular electoral stimulation) should be considered under the appropriate circumstances. Interval and continuous training modes generally have comparable improvements in exercise capacity, health-related quality of life, and skeletal muscle adaptations following training. Resistance training has been shown to provide greater increases in muscle mass and strength and to induce less dyspnea than endurance training, thereby making it an attractive alternative for individuals with severe dyspnea. The combination of strength training and endurance training provides many benefits when treating the severe muscle dysfunction in patients with chronic respiratory disease. Upper limb resistance endurance training improved upper limb function in COPD as well as functional task completion and fatigue scores. Neuromuscular electrical stimulation has been shown to improve leg muscle strength and exercise capacity and to reduce the dyspnea in stable outpatients with severe COPD and a poor baseline exercise tolerance.

Improvements in symptoms, exercise tolerance, and quality of life have also been shown in patients with other chronic lung diseases (eg, interstitial lung disease, pulmonary hypertension, and lung cancer). In addition, improvements in symptoms, exercise tolerance, and quality of life 
have been shown in symptomatic patients with COPD who have less air-flow obstruction than those who have more severe disease. Pulmonary rehabilitation should be considered for patients who have these types of chronic lung disease.

Pulmonary rehabilitation has been shown not only to be clinically effective and safe but also to be associated with other benefits. Its use has been shown to afford a reduction in subsequent hospital admissions for those patients who initiate rehabilitation shortly after a hospitalization for COPD exacerbation. Exercise rehabilitation started during an acute or critical illness has reduced the extent of functional decline and has helped to hasten recovery. It has also been shown to be effective when performed in a homebased setting by reducing dyspnea and increasing exercise performance in patients with COPD.

There is also an expansion of the assessment of outcomes associated with pulmonary rehabilitation. A broadened outcome assessment can now include a patient's COPD-related knowledge, self-efficacy, muscle function, balance, and physical activity. In addition, the importance of the recognition of other comorbidities, including anxiety and depression, is appreciated.

\section{Physiology (Exercise Training)}

The optimal exercise training intensity and/or strategy for individual patients with COPD remains unclear. A study by Klijn et al ${ }^{55}$ compared the effects of nonlinear periodized exercise (NLPE; which if often used in athletic training) to those of traditional endurance and progressive resistance training (EPR) in subjects with severe COPD. Subjects with severe COPD ( $n=110 ; \mathrm{FEV}_{1} 32 \%$ of predicted) were randomized to either a NLPE or EPR. Exercise training performed 3 times per week, for 10 weeks, was then provided. Outcome measures included cyclingendurance time and health-related quality of life as measured by the Chronic Respiratory Disease Questionnaire (CRQ).

NLPE resulted in significantly greater improvements in cycling endurance time compared with EPR (difference in change $+300.6 \mathrm{~s}, 95 \%$ CI $197-404 \mathrm{~s}, P<.001)$. NLPE also resulted in significantly greater improvements in all domains of the CRQ compared with EPR, ranging from 0.48 (95\% CI 0.19-0.78) for the emotion domain to 0.96 (95\% CI 0.57-1.35) for the dyspnea domain. It was concluded that NLPE resulted in greater improvements in cycle endurance and health-related quality of life in subjects with severe COPD compared to traditional training methods. Exercise training, identified as one of the most effective parts of pulmonary rehabilitation, and those training methods that are used for athletes may also be suitable for patients with severe COPD.

\section{Physiology (Arm Exercise)}

Arm exercise is another important component of exercise training for patients with COPD. Various types of instruction to patients while performing arm exercise (eg, inhaling while raising arms vs inhaling while lowering arms) have been provided during training sessions.

Dolmage et $\mathrm{al}^{56}$ performed a study to determine the effect of coordinated breathing with arm movements on endurance during a lifting task. This prospectively designed, interventional, double-blind, randomized controlled trial was performed on subjects with COPD and hyperinflation at rest. Participants $(n=360)$ were randomly assigned to one of 3 different groups, 2 interventions and one sham, where they received instruction on how to breathe during arm elevation (taught to inhale during the left, taught to exhale during the left, or unconstrained coordination). Each participant attended 2 baseline and 2 post-intervention assessment sessions that included a rhythmic arm elevation task. The tests were performed at a constant power at relatively high intensities per subject intolerance. The tolerable duration of a high-intensity constant power endurance test was used as the primary outcome measure.

There was an effect of group on the change in time to lifting intolerance $\left(\mathrm{t}_{\text {limit }}\right)(P<.01)$ regardless of the task intensity $(P=.47)$. The change in $\mathrm{t}_{\text {limit }}$ in the exhalation group was greater than that in both the sham group (difference of $2.82 \mathrm{~min}, 95 \%$ CI $0.21-5.44 \mathrm{~min}, P<.05$ ) and inhalation group (difference of 3.29 min, 95\% CI 0.65 $5.92 \mathrm{~min}, P<.05)$ at high intensity. No difference in the change in $t_{\text {limit }}$ between the inhalation and sham groups was noted. A specific breathing strategy, namely exhalation during lifting maneuvers, improved task performance, and the authors suggested that coordinating exhalation with lifting may be of value to those patients with COPD who have associated hyperinflation and who are engaged in arm and shoulder training exercises.

\section{Impact on Exacerbations and Health Care Utilization}

The impact of COPD exacerbations is a worldwide problem and is becoming better recognized. The impact of hospitalizations related to such exacerbations and the subsequent effects on physical activity are also becoming better understood. The benefits of rehabilitation for patients with COPD who are stable are well known; however, the effects of rehabilitation for patients who are recovering from an exacerbation are less well understood. A study by Revitt et $a^{57}$ was undertaken to evaluate the short-term effects of pulmonary rehabilitation for subjects who have been recently hospitalized for an exacerbation of COPD.

Subjects with a confirmed diagnosis of COPD $(n=160)$ were referred to the rehabilitation program following admission for an exacerbation. Each was individually as- 
sessed within 4 weeks of discharge from the hospital by a member of the rehabilitation team and completed standard outcome measures. Subjects were then referred to and attended twice-weekly pulmonary rehabilitation sessions for 4 weeks. Each subject continued a 3-week structured unsupervised home exercise program with each exercise session lasting $2 \mathrm{~h}$ with $1 \mathrm{~h}$ of education and $1 \mathrm{~h}$ of supervised exercise training. The exercise training included both walking and cycle ergometry that was individualized beginning at $85 \%$ of the subject's maximum $\dot{\mathrm{V}}_{\mathrm{O}_{2}}$ based on shuttle walk testing. In addition, resistance training of both upper and lower limbs and education training were provided. Outcome measures included the measurement of shuttle walk test distances, a health-related quality of life questionnaire (self-reported CRQ), and readmission data (total number of hospital days and number of hospital admissions). The readmission data were collected for the 12 months prior to the exacerbation and for the subsequent 12 months following hospital discharge.

Significant improvements were noted for both the incremental and endurance shuttle walk tests. The mean change in the incremental shuttle walk distance was $63.40 \mathrm{~m}$ (95\% CI 51.99-75.41, $P<.001$ ), whereas the mean change in the endurance shuttle walk time was $400.42 \mathrm{~s}(95 \%$ CI 330.49-470.34, $P<.001)$. Mean change in significant improvement in the self-reported CRQ domains of dyspnea, fatigue, emotion, and mastery were noted. The number of admissions was significantly less in the 12 months following pulmonary rehabilitation compared to the 12 months prior to entry into the rehabilitation program.

Readmission to the hospital following discharge from an exacerbation of COPD is an increasing problem throughout the world. Readmission rates within the first 30 days following hospitalization range from 20 to $25 \%$, and various types of programs are being developed in an attempt to reduce such hospital readmissions. Pulmonary rehabilitation, using the integrated care approach, can help to facilitate a reduction in such readmissions.

\section{Telerehabilitation}

COPD affects a significant number of people worldwide, being a leading cause of morbidity and mortality with significant impact on both individuals and communities. Despite the compelling evidence for the benefits associated with pulmonary rehabilitation, $<5 \%$ of subjects with COPD receive pulmonary rehabilitation yearly. Access to care is one of the factors that is associated with lack of subject entry into rehabilitation programs. Telehealth has an increasing role in the management of patients with COPD, and the use of telehealth strategies for pulmonary rehabilitation remains in its infancy. A study by Holland et $\mathrm{al}^{58}$ evaluated the safety and feasibility of home telerehabilitation for subjects with COPD.
Subjects with a confirmed diagnosis of COPD who were clinically stable entered into the program. An initial assessment of exercise capacity (6MWT), health-related quality of life (CRQ), and level of dyspnea (Modified Medical Research Council Dyspnea Scale) was performed. Telerehabilitation was conducted in each subject's home using a cycler ergometer. Oxyhemoglobin saturation and heart rate were measured with a pulse oximeter, and a tablet computer was used for videoconferencing. All participants were provided with a wireless $3 \mathrm{G}$ modem to connect to the internet. For 2 of the groups (4 participants), the clinician was located in the university and connected to the subject's home by the university data network, whereas for the other 2 groups (4 participants), the physiotherapy clinician was located in the hospital and connected via the hospital data network. Appropriate instruction was provided to each subject at home on the operation of the telehealth equipment at the beginning of the study.

Supervised exercise training was provided twice weekly for 8 weeks. Remote supervision of the exercise training for 2 subjects at a time was performed by the physiotherapist. The exercise program involved cycling with an intensity of $60 \%$ of peak work estimated from the initial 6MWT distance. Duration and intensity were increased according to standardized criteria. Monitoring of subject symptoms, heart rate, and oxygen saturation was performed. Informal discussions regarding self-management (eg, management of acute exacerbations and dealing with breathlessness) were led by the physiotherapist. The primary outcomes studied were adverse events, feasibility, and acceptability.

The COPD subjects (56-83 y old) in the study had a mean $\mathrm{FEV}_{1}$ of $60 \%$ of predicted; 2 had mild COPD, 4 had moderate COPD, and 2 had severe COPD. No subject required supplementary oxygen administration. No major adverse events were recorded. Minor adverse events were included desaturation to $<88 \%$ (one subject) and heart rate $>150$ beats/min ( 6 subjects). These events resolved with a reduction in exercise intensity, and no changes to the subsequent exercise prescription were required. Five of the 8 participants completed the program. Reasons for non-completion were related to exacerbations of the subject's underlying medical condition $(2$ subjects with a COPD exacerbation and one subject with an exacerbation of underlying diabetes). The feasibility and accessibility scores were high (94 of 100) in the groups for which the physiotherapist used the university data network but were lower (59 of 100) when the physiotherapist used the hospital data network. Most of the technical problems noted $(71 \%)$ were related to network connectivity. For those subjects who completed the program, improvements in secondary outcomes were clinically important for the 6MWT (mean $27 \mathrm{~m}$ ) and the CRQ dyspnea (4 units) and fatigue domains. 
Simple home-based telerehabilitation using readily available equipment is safe and feasible for patients with COPD. This study used cycle-based exercise training and could potentially, in many instances, be instituted in the home environment. The model used videoconferencing to allow direct supervision of participants by an experienced physiotherapist and thus provides potential for expansion for patients who have other chronic lung diseases. The benefits of telerehabilitation in this small sample provide a rationale for ongoing testing in large randomized controlled trials.

\section{COPD and Comorbidities (eg, Sleep-Related Disorders)}

Patients with COPD often have several associated comorbidities. Sleep-related disorders are often not considered as an associated comorbidity for such patients. In addition, the effects of pulmonary rehabilitation on sleep quality are not known. Soler et al ${ }^{59}$ evaluated the effect of pulmonary rehabilitation on sleep quality in subjects with chronic lung disease and explored the relationships between poor sleep quality and quality of life in these subjects.

This prospective observational study included subjects with chronic lung disease who were enrolled in a comprehensive pulmonary rehabilitation program over a 1-y period. Outcome measures included exercise tolerance (6MWT distance), sleep quality (Pittsburgh Sleep Quality Index), health-related quality of life (SF-36), dyspnea (UCSD Shortness of Breath Questionnaire), and self-efficacy for walking. Sixty-four subjects completed all preand post-program assessments.

Overall sleep quality improved by $19 \%(P=.02)$ after pulmonary rehabilitation. Significant improvements in dyspnea, exercise tolerance, self-efficacy, and health-related quality of life were also noted. While sleep quality in subjects with chronic lung disease was poor, the subgroup of subjects with COPD had a significant improvement in sleep quality. These findings suggest that sleep quality in patients with chronic lung disease should be evaluated as part of the comorbidity evaluation. They also suggest that pulmonary rehabilitation may be an effective nonpharmacologic treatment option for sleep difficulties in these patients.

\section{Other General Review Articles}

In addition to these articles, several review articles were published (eg, exercise training strategies, activity of daily living [ADL] measures, and use of maintenance rehabilitation). The latest research findings regarding exercise in patients with COPD were reviewed, and practical recommendations for exercise were made that focused on useful assessment tests and the most common exercise modalities for patients with COPD. Specific details on the rationale behind the implementation of various types of exercise training (including mode, intensity, duration, and guidelines for progression) were discussed. This article provides an excellent review of the tenets of exercise training. ${ }^{60}$

A systematic review of the measures of ADLs that have been used in patients with COPD was performed. ${ }^{61}$ The authors' review identified 11 instruments that were respiratory disease-specific and 16 that were generic. Most combined instrumental ADLs with basic ADLs, with the majority of instruments being self-reported. Psychometric properties have been reported only for a few of these instruments. Selection of the best measure for ADLs for an individual patient (or group) should focus on the target construct (basic or instrumental ADL), type of test (disease-specific vs generic), and psychometric properties of the instrument.

Continuation of pulmonary rehabilitation beyond the initial program (ie, maintenance rehabilitation) has been a subject of debate over the last several decades. Beauchamp et al ${ }^{62}$ published a systematic review to determine the effect of supervised exercise programs after the primary program on exercise capacity and health-related quality of life in patients with COPD. Seven randomized controlled trials (total of 619 individuals) with moderate-to-severe COPD were evaluated. They concluded that such programs appear to be more effective than usual care for preserving exercise capacity in the medium term ( 6 months) but not the long term (12 months). There was no effect on healthrelated quality of life. They proposed that the small number of studies precluded any definitive conclusions as to the impact of post-rehabilitation exercise maintenance on long-term benefits.

\section{Summary}

In this paper, the important recent literature on neonatal respiratory care, pulmonary function testing, and pulmonary rehabilitation is reviewed. It is our hope that this will help to familiarize the reader with the important literature in these subject areas.

\section{REFERENCES}

1. Elective high-frequency oscillatory ventilation versus conventional ventilation for acute pulmonary dysfunction in preterm infants. Neonatology 2013;103(1):7-8; discussion 8-9.

2. Tingay DG, Mills JF, Morley CJ, Pellicano A, Dargaville PA. Indicators of optimal lung volume during high-frequency oscillatory ventilation in infants. Crit Care Med 2013;41(1):237-244.

3. Venegas JG, Harris RS, Simon BA. A comprehensive equation for the pulmonary pressure-volume curve. J Appl Physiol 1998;84(1): 389-395. 


\section{Respiratory CARE Year In Review 2013}

4. Morley CJ, Davis PG, Doyle LW, Brion LP, Hascoet JM, Carlin JB. Nasal CPAP or intubation at birth for very preterm infants. N Engl J Med 2008;358(7):700-708.

5. SUPPORT Study Group of the Eunice Kennedy Shriver NICHD Neonatal Research Network, Finer NN, Carlo WA, Walsh MC, Rich W, Gantz MG, et al. Early CPAP versus surfactant in extremely preterm infants. N Engl J Med 2010;362(21):1970-1979.

6. Wilinska M, Bachman T, Swietlinski J, Gajewska E, Meller J, Helwich $\mathrm{E}$, et al. Impact of the shift to neonatal noninvasive ventilation in Poland: a population study. Pediatr Crit Care Med 2014;15(2): 155-161.

7. Davis PG, Lemyre B, de Paoli AG. Nasal intermittent positive pressure ventilation (NIPPV) versus nasal continuous positive airway pressure (NCPAP) for preterm neonates after extubation. Cochrane Database Syst Rev 2001;(3):CD003212.

8. Lemyre B, Davis PG, de Paoli AG. Nasal intermittent positive pressure ventilation (NIPPV) versus nasal continuous positive airway pressure (NCPAP) for apnea of prematurity. Cochrane Database Syst Rev 2002;(1):CD002272.

9. Meneses J, Bhandari V, Alves JG. Nasal intermittent positive-pressure ventilation vs nasal continuous positive airway pressure for preterm infants with respiratory distress syndrome: a systematic review and meta-analysis. Arch Pediatr Adolesc Med 2012;166(4): 372-376.

10. Kirpalani H, Millar D, Lemyre B, Yoder BA, Chiu A, Roberts RS, NIPPV Study Group. A trial comparing noninvasive ventilation strategies in preterm infants. N Engl J Med 2013;369(7):611-620.

11. American Academy of Pediatrics. Committee on Fetus and Newborn. Use of inhaled nitric oxide. Pediatrics 2000;106(2 Pt 1):344345.

12. Konduri GG, Solimano A, Sokol GM, Singer J, Ehrenkranz RA, Singhal N, et al. A randomized trial of early versus standard inhaled nitric oxide therapy in term and near-term newborn infants with hypoxic respiratory failure. Pediatrics 2004;113(3 Pt 1):559-564.

13. Konduri GG, Sokol GM, Van Meurs KP, Singer J, Ambalavanan N, Lee T, Solimano A. Impact of early surfactant and inhaled nitric oxide therapies on outcomes in term/late preterm neonates with moderate hypoxic respiratory failure. J Perinatol 2013;33(12):944-949.

14. McCurnin DC, Pierce RA, Chang LY, Gibson LL, Osborne-Lawrence S, Yoder BA, et al. Inhaled NO improves early pulmonary function and modifies lung growth and elastin deposition in a baboon model of neonatal chronic lung disease. Am J Physiol Lung Cell Mol Physiol 2005;288(3):L450-L459.

15. Pansiot J, Loron G, Olivier P, Fontaine R, Charriaut-Marlangue C, Mercier JC, et al. Neuroprotective effect of inhaled nitric oxide on excitotoxic-induced brain damage in neonatal rat. PLoS One 2010; 5(6): 10916.

16. Durrmeyer X, Hummler H, Sanchez-Luna M, Carnielli VP, Field D, Greenough A, et al. Two-year outcomes of a randomized controlled trial of inhaled nitric oxide in premature infants. Pediatrics 2013; 132(3):e695-703.

17. Rosenfeld M, Allen J, Arets BH, Aurora P, Beydon N, Calogero C, et al. An official American Thoracic Society workshop report: optimal lung function tests for monitoring cystic fibrosis, bronchopulmonary dysplasia, and recurrent wheezing in children less than 6 years of age. Ann Am Thorac Soc 2013;10(2):S1-S11.

18. Parsons JP, Hallstrand TS, Mastronarde JG, Kaminsky DA, Rundell $\mathrm{KW}$, Hull JH, et al. An official American Thoracic Society clinical practice guideline: exercise-induced bronchoconstriction. Am J Respir Crit Care Med 2013;187(9):1016-1027.

19. Enright PL, Johnson LR, Connett JE, Voelker H, Buist AS. Spirometry in the Lung Health Study. 1. Methods and quality control. Am Rev Respir Dis 1991;143(6):1215-1223.
20. Bellia V, Pistelli R, Catalano F, Antonelli-Incalzi R, Grassi V, Melillo G, et al. Quality control of spirometry in the elderly: the S.A.R.A. study. Am J Respir Crit Care Med 2000;161(4 Pt 1):1094-1100.

21. Pérez-Padilla R, Vázquez-García JC, Márquez MN, Menezes AM, PLATINO Group. Spirometry quality-control strategies in a multinational study of the prevalence of chronic obstructive pulmonary disease. Respir Care 2008;53(8):1019-1026.

22. Enright PL, Skloot GS, Cox-Ganser JM, Udasin IG, Herbert R. Quality of spirometry performed by 13,599 participants in the World Trade Center Worker and Volunteer Medical Screening Program. Respir Care 2010;55(3):303-309.

23. Borg BM, Hartley MF, Bailey MJ, Thompson BR. Adherence to acceptability and repeatability criteria for spirometry in complex lung function laboratories. Respir Care 2012;57(12):2032-2038.

24. Seyedmehdi SM, Attarchi M, Yazdanparast T, Lakeh MM. Quality of spirometry tests and pulmonary function changes among industrial company workers in Iran: a two-year before-and-after study following an intensive training intervention. Prim Care Respir J 2013; 22(1):86-91.

25. Enright P, Schermer T. Don't pay for poor quality spirometry tests. Prim Care Respir J 2013;22(1):15-16.

26. Haynes JM. Pulmonary function test quality in the elderly: a comparison with younger adults. Respir Care 2014;59(1):16-21.

27. Quanjer PH, Stanojevic S, Cole TJ, Baur X, Hall GL, Culver BH, et al. Multi-ethnic reference values for spirometry for the 3-95-yr age range: the global lung function 2012 equations. Eur Respir J 2012; 40(6):1324-1343.

28. Edvardsen E, Scient C, Hansen BH, Holme IM, Dyrstad SM, Anderssen SA. Reference values for cardiorespiratory response and fitness on the treadmill in a 20- to 85-year-old population. Chest 2013;144(1):241-248.

29. Schulz H, Flexeder C, Behr J, Heier M, Holle R, Huber RM, et al. Reference values of impulse oscillometric lung function indices in adults of advanced age. PLoS One 2013;8(5):e63366.

30. Lum S, Stocks J, Stanojevic S, Wade A, Robinson P, Gustafsson P, et al. Age and height dependence of lung clearance index and functional residual capacity. Eur Respir J 2013;41(6):1371-1377.

31. Stanojevic S, Wade A, Stocks J. Reference values for lung function: past, present and future. Eur Respir J 2010;36(1):12-19.

32. Miller MR, Quanjer PH, Swanney MP, Ruppel G, Enright PL. Interpreting lung function data using $80 \%$ predicted and fixed thresholds misclassifies more than $20 \%$ of patients. Chest 2011;139(1):5259.

33. Culver BH. How should the lower limit of the normal range be defined? Respir Care 2012;57(1):136-145; discussion 143-145.

34. Quanjer PH, Weiner DJ. Interpretive consequences of adopting the global lungs 2012 reference equations for spirometry for children and adolescents. Pediatr Pulmonol 2014;49(2):118-125.

35. Hankinson JL, Odencrantz JR, Fedan KB. Spirometric reference values from a sample of the general U.S. population. Am J Respir Crit Care Med 1999;159(1):179-187.

36. Wang X, Dockery DW, Wypij D, Fay ME, Ferris BG Jr. Pulmonary function between 6 and 18 years of age. Pediatr Pulmonol 1993;15: 75-88.

37. Knudson RJ, Lebowitz MD, Holberg CJ, Burrows B. Changes in the normal maximal expiratory flow-volume curve with growth and aging. Am Rev Respir Dis 1983;127(6):725-734.

38. Polgar G, Promadhat V. Pulmonary function testing in children: techniques and standards. Philadelphia: WB Saunders Co; 1971.

39. Zapletal A, Paul T, Samánek N. [Die Bedeutung heutiger Methoden der Lungenfunktionsdiagnostik zur Feststellung einer Obstruktion der Atemwege bei Kindern und Jugendlichen]. Z Erkr Atmungsorgane 1977;149(3):343-371. Article in German. 


\section{Respiratory CARE Year In Review 2013}

40. Quanjer PH, Brazzale DJ, Boros PW, Pretto JJ. Implications of adopting the Global Lungs Initiative 2012 all-age reference equations for spirometry. Eur Respir J 2013;42(4):1046-1054.

41. Quanjer PH, Tammeling GJ, Cotes JE, Pedersen OF, Peslin R, Yernault JC. Lung volumes and forced ventilatory flows. Report Working Party Standardization of Lung Function Tests, European Community for Steel and Coal. Official Statement of the European Respiratory Society. Eur Respir J Suppl 1993;16:5-40.

42. ATS Committee on Proficiency Standards for Clinical Pulmonary Function Laboratories. ATS statement: guidelines for the six-minute walk test. Am J Respir Crit Care Med 2002;166(1):111-117.

43. Savarese G, Paolillo S, Costanzo P, D'Amore C, Cecere M, Losco T, et al. Do changes of 6-minute walk distance predict clinical events in patients with pulmonary arterial hypertension? A meta-analysis of 22 randomized trials. J Am Coll Cardiol 2012;60(13):1192-1201.

44. Dolmage TE, Hill K, Evans RA, Goldstein RS. Has my patient responded? Interpreting clinical measurements such as the 6-minutewalk test. Am J Respir Crit Care Med 2011;184(6):642-646.

45. Weir NA, Brown AW, Shlobin OA, Smith MA, Reffett T, Battle E, et al. The influence of alternative instruction on 6-min walk test distance. Chest 2013;144(6):1900-1905.

46. Ahmadian HR, Sclafani JJ, Emmons EE, Morris MJ, Leclerc KM, Slim AM. Comparison of predicted exercise capacity equations and the effect of actual versus ideal body weight among subjects undergoing cardiopulmonary exercise testing. Cardiol Res Pract 2013; 2013:940170.

47. Kaminsky DA, Knyazhitskiy A, Sadeghi A, Irvin CG. Assessing maximal exercise capacity: peak work or peak oxygen consumption? Respir Care 2014;59(1):90-96.

48. Petty TL. John Hutchinson's mysterious machine revisited. Chest 2002;121(5 Suppl):219S-223S.

49. Majid A, Sosa AF, Ernst A, Feller-Kopman D, Folch E, Singh AK, Gangadharan S. Pulmonary function and flow-volume loop patterns in patients with tracheobronchomalacia. Respir Care 2013;58(9):15211526.

50. Nozoe M, Mase K, Murakami S, Okada M, Ogino T, Matsushita K, et al. Relationship between spontaneous expiratory flow-volume curve pattern and air-flow obstruction in elderly COPD patients. Respir Care 2013;58(10):1643-1648.
51. Morris ZQ, Coz A, Starosta D. An isolated reduction of the $\mathrm{FEV}_{3} / \mathrm{FVC}$ ratio is an indicator of mild lung injury. Chest 2013;144(4):1117-1123.

52. Nici L, Donner C, Wouters E, ZuWallack R, Ambrosino N, Bourbeau J, et al. American Thoracic Society/European Respiratory Society statement on pulmonary rehabilitation. Am J Respir Crit Care Med 2006;173(12):1390-1413.

53. Ries AL, Bauldoff GS, Carlin BW, Casaburi R, Emery CF, Mahler DA, et al. Pulmonary rehabilitation: joint ACCP/AACVPR evidencebased clinical practice guidelines. Chest 2007;131(5 Suppl):4S-42S.

54. Spruit MA, Singh SJ, Garvey C, ZuWallack R, Nici L, Rochester C, et al. An official American Thoracic Society/European Respiratory Society Statement: key concepts and advances in pulmonary rehabilitation. Am J Respir Crit Care Med 2013;188(8):e16-e64.

55. Klijn P, van Keimpema A, Legemaat M, Gosselink R, van Stel H. Nonlinear exercise training in advanced COPD is superior to traditional exercise training. Am J Respir Crit Care Med 2013;188(2): 193-200.

56. Dolmage TE, Janaudis-Ferreira T, Hill K, Price S, Brooks D, Goldstein RS. Arm elevation and coordinated breathing strategies in patients with COPD. Chest 2013;144(1):128-135.

57. Revitt O, Sewell L, Morgan MD, Steiner M, Singh S. A short outpatient pulmonary rehabilitation programme reduces readmission following a hospitalization for an exacerbation of COPD. Respirology 2013;18(7):1063-1068

58. Holland AE, Hill CJ, Rochford P, Fiore J, Berlowitz DJ, McDonald CF. Telerehabilitation for people with chronic obstructive pulmonary disease: feasibility of a simple, real time model of supervised exercise training. J Telemed Telecare 2013;19(4):222-226.

59. Soler X, Diaz-Piedra C, Ries AL. Pulmonary rehabilitation improves sleep quality in chronic lung disease. COPD 2013;10(2):156-163.

60. Gloeckl R, Marinov B, Pitta F. Practical recommendations for exercise training in patients with COPD. Eur Respir Rev 2013;22(128): 178-186.

61. Janaudis-Ferreira T, Beauchamp MK, Robles PG, Goldstein RS, Brooks D. Measurement of activities of daily living in COPD: a systematic review. Chest 2014;145(2):253-271.

62. Beauchamp MK, Evans R, Janaudis-Ferreira T, Goldstein RS, Brooks D. Systematic review of supervised exercise programs after pulmonary rehabilitation individuals with COPD. Chest 2013;144(4):11241133. 